\title{
A Thermodynamic Model of an Arctic Lead
}

\author{
R. H. SCHAUS and J. A. GALT ${ }^{1}$
}

\begin{abstract}
A time-dependent, two-dimensional thermodynamic model of an open lead in central arctic sea ice is presented. The effects of various advective parameterizations and temperature and salinity profiles on the nature of ice formation are investigated as the lead refreezes. Velocity and stratification under the lead appear to impose secondary but significant constraints on the rate of refreezing. This suggests the existence of regional variations in the heat loss per lead as a function of purely oceanographic factors.
\end{abstract}

RÉSUMÉ. Modèle thermodynamique d'un chenal arctique. Les auteurs présentent un modèle thermodynamique lié au temps, à deux dimensions, d'un chenal ouvert dans la glace de mer de l'Arctique central. Au moment où le chenal recongèle, les auteurs étudient les effets des divers paramètres d'advection et des profils de température et de salinité sur la nature de la formation de la glace. La vélocité et la stratification de l'eau sous le chenal semblent imposer des contraintes secondaires mais significatives sur le rythme de regel. Ceci suggère l'existence de variations régionales dans la déperdition de chaleur par chenal en fonction de facteurs purement océanographiques.

\begin{abstract}
РЕЗЮМЕ. Термодинамическая модель арктического разводљл. ІІредставлена зависящая от времени двухмерная термодинамическая модель разводья в морских льдах центральной Арктики. В процессе замерзания разводья исследовалось влияние различных параметров, включая профили темгератур и солёности, на характер образования льда. Оказалось, что скорость и стратификация воды под разводьем налагают вторичные, но существенные ограничения на скорость замерзания. Это указывает на существование региональных изменений величины тепловых потерь на одно равводье в зависимости от чисто океанографических факторов.
\end{abstract}

\section{INTRODUCTION}

Attempts to understand the nature of arctic air-sea interactions have long stimulated the interest of arctic researchers. The Arctic, being an ice-covered ocean, is extremely sensitive to climatic variations. Oceanic and atmospheric perturbations influence the thickness and the areal extent of sea ice, which in turn profoundly affect the thermal exchange and the regional energy balance. Quantitative understanding of the arctic thermal regime has been significantly enhanced by recent arctic heat budget studies (Badgley 1961, 1966; Vowinckel 1964; Coachman 1966; Doronin 1966; Fletcher 1966; Muench 1971).

Of major importance to arctic air-sea interactions is the degree to which the sea surface is covered by ice, since sea ice acts analogously to a 'lid' on the sea, modifying the dynamics of the air-sea system. Quantitative predictions of the response of sea ice to environmental changes range in method of approach from the empirical (Bilello 1961), through the analytical, exemplified by Kolesnikov's model as analyzed by Mettler and Stehle (1966), to the sophisticated numerical sea ice model of Maykut and Untersteiner $(1969,1971)$ which provides insights into the dynamics of the physical processes occurring as well as accomplishing basic predictive goals.

1Department of Oceanography, Naval Postgraduate School, Monterey, California, U.S.A. 
The mezoscale role played by patchiness in the arctic sea ice cover on the regional mass-energy balance, however, is still not well understood. Wind and water stresses maintain the sea ice in nearly continuous motion, producing thermally active polynia and open leads. Maykut and Untersteiner's sea ice model investigated the role of each component of the energy budget in relation to its effects on the ice, while predicting ice thickness and temperature. In their model leads were considered only so far as they indirectly affected the energy fluxes over the bare ice. One of their principal recommendations therefore (Maykut and Untersteiner 1971) was that a suitable model of oceanic convection under icecovered and ice-free surfaces be developed in order to approach the central problem of transition from an ice-free to an ice-covered Arctic Ocean.

The principal objective of the work at hand was to gain insight into the hydrothermodynamic processes occurring in a typical central arctic open lead during thermal reclosure. A concurrent objective was to ascertain if the work could be conceptually coupled with the sea ice model of Maykut and Untersteiner to gain additional knowledge of the aforementioned central problem of transition.

It is known that significant heat transfer occurs between the atmosphere and the ocean through open leads in the arctic sea ice cover. As found experimentally by Badgley (1961), sensible heat loss is at least two orders of magnitude greater from open leads than from perennial sea ice. It is not known to what extent this high heat flux depends on the stability or advection of the underlying ocean environment; neither is it clear as to how effective the patchiness of the ice-lead structure is in controlling the dominant horizontal scales of the upper layer in the Arctic Ocean, or for that matter, what these scales are.

The structure of the active surface layer of the Arctic Ocean is generally horizontally uniform with a very stable sensity gradient. However, during the freezing process the density gradient may be significantly altered by three primary mechanisms: 1) progressive cooling of surface waters from above, 2) brine expulsion by ice during the freezing process, and 3) advection of heat and/or salt by surface currents. Any process that tends to produce a vertical density instability will induce convective overturn in the water column, resulting in mixing of the unstable segment. Convective overturn will therefore be continuous in the unstable segment of the liquid water column from the onset of surface cooling to the point of total change-of-phase of the water column. A somewhat less obvious but straightforward point should be mentioned in qualification of the foregoing. From an arbitrary water temperature above the freezing point, down to but not including the freezing point, convection is temperature-controlled during cooling since no ice is formed, hence there is no brine expulsion. During cooling of surface waters at the freezing point for existing surface salinities, convection is primarily salinity-controlled since brine is being continuously expelled from newly forming ice. Within this latter water temperature regime, temperature changes play a minor role in effecting changes in surface water densities. As convective overturn is a mechanism for inhibiting freezing by continuously transferring heat from depth to the active boundary at which freezing is taking place, so it is also a mechanism for effectively removing heat from depths significantly greater than could be effected by molecular diffusion. An equilibrium ice thickness is reached when the resultant heat flux upward through convection, advection, and diffusion 
in the water column balances the upward resultant heat flux through the ice at the ice-water boundary. Prior to this point ice is accreted in depth since the upward heat flux through the ice exceeds the upward heat flux in the water column arriving at the ice-water boundary.

\section{EXPERIMENTAL PROCEDURE}

The essence of this study was the development of a thermodynamic model of an open lead in central arctic sea ice in which hydrodynamic processes of convection, advection and diffusion of heat and salt were represented. By integrating the model numerically, the effects of various representative advective parameterizations and temperature and salinity profiles in the ocean's surface layer on the heat flux through the lead and on the nature of ice formation could be investigated, as the lead reclosed by thermal processes alone.

A small open lead in central arctic sea ice such as one would expect to observe between early to late winter was modelled. The width of the ice-free lead surface was chosen to be $150 \mathrm{~m}$., with an additional $50 \mathrm{~m}$. represented under equilibrium sea ice cover on the downstream side of the model to facilitate studying resultant thermodynamics and hydrodynamics in that region. The model's depth extent was set at $50 \mathrm{~m}$. since, over much of the Arctic Basin, the vertical temperature gradient at that depth is zero or very slightly positive, and a no-flux lower boundary condition was desirable in order better to study the effects of advection in the lead.

The basic continuity equation used to describe the local changes in concentration of a conservative constituent, ${ }_{\infty}(t, x, y, z)$, in the waters of the lead due to eddy diffusion and advection was

$$
\frac{\partial \phi}{\partial \mathrm{t}}=-\phi(\bar{\nabla} \cdot \overline{\mathrm{V}})-\overline{\mathrm{V}} \cdot \bar{\nabla} \phi+\mathrm{K}\left(\nabla^{2} \phi\right)
$$

where $K$ is a constant-valued kinematic eddy diffusivity and $\vec{V}$ is the Cartesian current-velocity vector. The model was simplified without the loss of essential physics by setting derivatives along the lead (y-axis) to zero, thus reducing the problem to one of looking at a cross-sectional distribution in the lead. Therefore, the horizontal diffusion term describing changes in the y-direction was eliminated. and the distribution of constituents is unaffected by flow along the lead. The problem was further simplified by assuming that all horizontal diffusion was negligible in relation to horizontal advection, that vertical advection could be disregarded, and that the velocity field in the lead was non-divergent. The process of convection was introduced to the basic continuity equation through the conceptual artifice of allowing the vertical eddy diffusivity constant to approach infinity whenever vertical instability occurred. Applying the foregoing to the basic equation, and choosing the state variables of temperature (T) and salinity (S) as the relevant dependent variables, the final forms of the equations used to describe these conservative scalar fields within the refreezing lead were

$$
\frac{\partial \mathrm{T}}{\partial \mathrm{t}}=-\mathrm{u}\left(\frac{\partial \mathrm{T}}{\partial \mathrm{x}}\right)+\mathrm{K}\left(\frac{\partial^{2} \mathrm{~T}}{\partial \mathrm{z}^{2}}\right) \quad \frac{\partial \mathrm{S}}{\partial \mathrm{t}}=-\mathrm{u}\left(\frac{\partial \mathrm{S}}{\partial \mathrm{x}}\right)+\mathrm{K}\left(\frac{\partial^{2} \mathrm{~S}}{\partial \mathrm{z}^{2}}\right)
$$

where $\mathrm{u}$ is the component of current velocity in the $\mathrm{x}$-direction. 
Sea water temperatures and salinities within the lead at the instant of lead generation are represented by steady-state, horizontally uniform temperature and salinity fields previously existing beneath the equilibrium sea ice. Surface temperatures are initially at the freezing point, in temperature equilibrium with the preexisting sea ice. The model's left, or upstream boundary, may be regarded as a source boundary across which sea water flows into the lead. Sea water temperature and salinity profiles at this boundary are steady-state functions of depth alone, identical to the lead's initial temperature and salinity fields. The model's surface boundary is the primary region of mass and energy fluxes and is therefore the most dynamically active boundary. The boundary condition on temperature across the entire surface is that of an upward (or downward) diffusive flux of heat across the water surface so that

$$
\frac{\partial}{\partial z}[T(t, x, O)]=f\left(\Delta T, Z_{i}, S_{i}, K, K_{i}\right)
$$

where $\Delta \mathrm{T}$ is the air-water temperature difference (externally specified), $Z_{i}$ is the surface ice thickness, $S_{i}$ is the surface ice salinity (externally specified), $K$ is the eddy diffusivity of sea water, and $K_{i}$ is the thermal conductivity of sea ice. The boundary condition on sea water salinity at the surface specifies a no-diffusive flux condition between air and water as well as between ice and water and ice and air. However, salt rejection from ice to water during the freezing process (as well as salt dilution during melting) is represented by a discrete process of physically adding the change in salinity produced by sea ice accretion or melting to the surface waters. Sea ice formed in the model was represented as having a constant salinity of $8 \%$, representative of young sea ice, since the time scale of lead reclosure is very short in relation to the time scale of progressive salt drainage in aging ice. For a more rigid treatment of the salt rejection process, see Foster (1968, 1969), Lake and Lewis (1970), Stern and Turner (1969), and Lewis and Walker (1970).

The bottom boundary as previously mentioned is portrayed as a no-flux boundary. The right, or downstream boundary, is characterized as a no-diffusive-flux boundary where whatever temperature-salinity field is generated by lead thermodynamics is simply advected out. However, as previously mentioned, the right $50 \mathrm{~m}$. of the model's surface is overlain by an equilibrium sea ice cover. This boundary condition is therefore representative of a return to the equilibrium state. Fig. 1 schematically represents the model with its governing continuity equations and boundary conditions.

Convective overturn and its associated mixing is accomplished through arithmetic averaging of temperatures and salinities within regions of vertical density instability as determined by sigma-t values, followed by recomputation of the resultant sigma-t value for the newly mixed region. Advection of heat and salt in the lead is driven by a current, $\mathrm{u}$, in the positive $\mathrm{x}$-direction. In order to ascertain the influence of advection on the lead thermodynamics, the current was chosen to be constant with depth, flowing directly across the lead. Diffusion of heat and salt in the vertical is determined by the kinematic vertical eddy diffusivity. Since convection was the dominant process driving vertical transport of heat and 
salt initially in the model, a single representative value of vertical eddy diffusivity, $10 \mathrm{~cm} .{ }^{2} \mathrm{sec} .^{-1}$, invariant with depth, was chosen for simplicity to govern vertical eddy diffusion of both heat and salt within vertically stable regions. Within unstable regions, diffusion was effectively replaced by convection as a vertical transport process through the aforementioned conceptual artifice of allowing the vertical eddy diffusivity to approach infinity.

Environmental data used in the model fell into two basic categories: that which remained constant throughout all runs of the model, and that which was variable from run-to-run. Representative of the former were ice salinity, ice density, initial equilibrium ice thickness ( $2 \mathrm{~m}$.), and open-water surface heat flux densities. Using as guides the observations (Badgley 1966) and calculations (Muench 1971) of open lead energy budgets, open-water surface heat flux densities applied in the model were (cal. $\mathrm{cm}^{-2} \mathrm{sec}^{-1}$ ): sensible, $15.0 \times 10^{-3}$; latent, $3.0 \mathrm{x}$ $10^{-3}$; and net-radiative (incoming solar radiation plus net back-radiation), $2.0 \mathrm{x}$ $10^{-3}$. Consistent with the above studies, as ice formed in the model the latent and net-radiative surface heat flux densities were assumed to decrease as con-

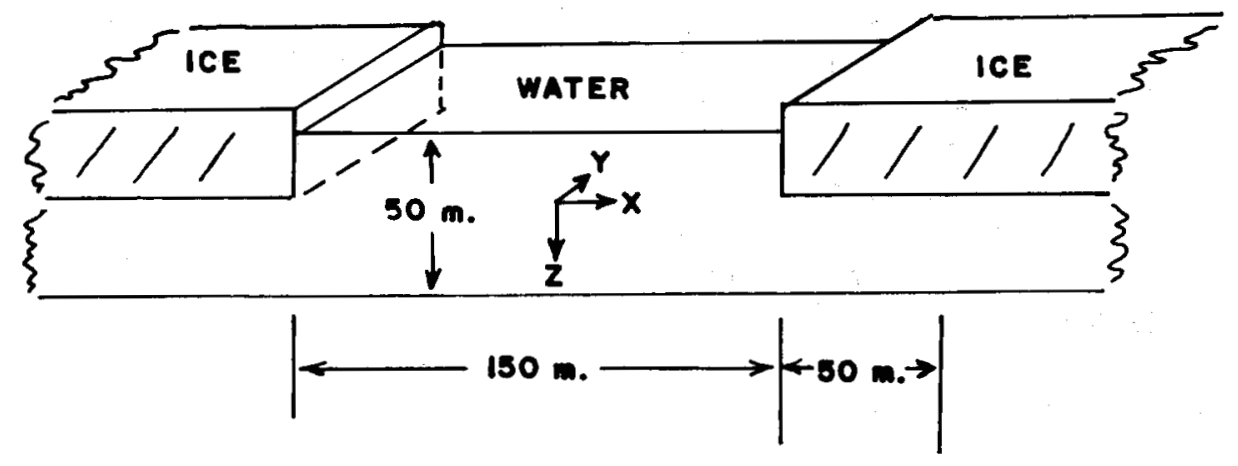

$$
\begin{aligned}
& \frac{\partial T}{\partial z}_{\text {water }}=\begin{array}{l}
\frac{F_{\Sigma}}{K}, z_{i}=0 \\
\frac{K_{i}}{K} \frac{\partial T}{\partial z}-\frac{\rho_{i} q_{i}}{K} \frac{\partial z}{\partial t} i, z_{i}>0
\end{array} \\
& \frac{\partial S}{\partial z}=0 \\
& \mathrm{~T}=\mathrm{T}(\mathrm{z})\left[\begin{array}{ll}
\frac{\partial \mathrm{T}}{\partial \mathrm{t}}=-\mathrm{u} \frac{\partial \mathrm{T}}{\partial \mathrm{x}}+\mathrm{K} \frac{\partial^{2} \mathrm{~T}}{\partial \mathrm{z}^{2}} & \mathrm{~s}(\mathrm{z})\left[\begin{array}{l}
\mathrm{z}_{\mathrm{i}}=2 \mathrm{~m} \\
\frac{\partial \mathrm{S}}{\partial \mathrm{t}}=-\mathrm{u} \frac{\partial \mathrm{S}}{\partial \mathrm{x}}+\mathrm{K} \frac{\partial^{2} \mathrm{~S}}{\partial \mathrm{z}^{2}}
\end{array}\right. \\
\frac{\partial \mathrm{S}}{\partial \mathrm{x}}=0
\end{array}\right. \\
& \frac{\partial \mathrm{T}}{\partial \mathrm{z}}=0 \quad \frac{\partial \mathrm{S}}{\partial \mathrm{z}}=0
\end{aligned}
$$

FIG. 1. Schematic depiction of the open lead with governing continuity equations and boundary conditions. The surface boundary condition states the balance of fluxes at the ice-water boundary. With no ice present $\left(Z_{i}=0\right)$, the upward heat flux through the water surface, $F \epsilon$, is equal to the sum of the open-water sensible $\left(F_{s}\right)$, latent $\left(F_{e}\right)$, and net-radiative $\left(F_{r}\right)$ heat fluxes. When ice is present $\left(\mathrm{Z}_{\mathrm{i}}>0\right)$, the upward heat flux through the water surface $\left(\mathrm{z}=0^{+}\right)$is equal to the upward heat flux through the ice $\left(\mathrm{z}=0^{-}\right)$minus the heat added by surface ice accretion. $\rho_{\mathrm{i}}$ is the volume density of sea ice and $q_{i}$ its heat of formation. 
tinuous functions from the foregoing open-water values, reaching constant values of 0.0 and $0.7 \times 10^{-3} \mathrm{cal} . \mathrm{cm}^{-2} \mathrm{sec}^{-1}$, respectively, for ice thicknesses greater than $1.0 \times 10^{-6} \mathrm{~cm}$. Sensible surface heat flux densities for ice-covered surfaces were calculated using the relation depicted in Fig. 1, commencing with the onset of ice formation. All surface heat flux densities were representative of an air-water temperature difference of $25^{\circ} \mathrm{C}$. with no wind.

Environmental data which varied from run-to-run were horizontal current magnitude and vertical temperature and salinity profiles. Table 1 is a summary of these primary variables as applied in the model. In order to gain maximum insight into physical processes occurring in the lead, test case profiles of extreme values of these variables were used, represented by profiles A (strong current, strong temperature and salinity gradients) and profiles B (weak current, weak temperature and salinity gradients). Additional test case profiles C, D, and F of horizontal current magnitudes were used to study the hydrodynamics of one particular temperature-salinity field in further detail. Real case profiles used in the model were chosen as typically occurring values and are represented as horizontal current magnitude profile $E$ (arbitrarily chosen), and temperature and salinity profiles $C$ (early winter) and $D$ (late winter) according to Coachman and Barnes (1961, 1962). Table 2 is a summary of runs conducted. Runs 1 to 8 represent studies of all possible combinations of test case profiles $\mathbf{A}$ and $\mathbf{B}$. Runs 9, 10 and 14 represent additional test case studies of the hydrodynamics of one particular temperature-salinity field. Runs 11,12 and 13 represent real case studies. Lead age in days, starting from the moment of generation, is represented by "Period of integration".

A purely explicit finite difference scheme was used to represent numerically the linear parabolic partial differential equation of continuity. The time-rate-ofchange term was represented by forward differencing, the field-rate-of-change term by backward (upstream) differencing, and the diffusive term by central differencing. Use of this scheme permitted the employment of a 90 -second time increment with a maximum current of $10 \mathrm{~cm}$. sec. ${ }^{-1}$, a vertical grid space of $5 \mathrm{~m}$., and a horizontal grid space of $10 \mathrm{~m}$. The computer program was written in FORTRAN IV and used with the IBM 360/67 computer system. Integration of the model required on the average of 1 minute of computer time for each 5.2 hours modelled. The program was generalized so that sea water temperature and salinity profiles were treated as input data. A design feature of the program allows the use of an internally variable time step to facilitate adjusting the model's temporal resolution, as well as allowing variable grid spacing and lead dimensioning. Although not used in the work at hand, the model also is designed to employ spatially-variable horizontal current magnitudes and vertical eddy diffusivities. For a complete description of the numerical techniques involved see Schaus (1971).

In addition to the assumptions made earlier in arriving at the simplified model of an open lead, basic limitations in the model's capabilities are: 1) the atmosphere is treated as an external parameter so that it affects lead dynamics but cannot be affected in turn by the lead; 2) sea ice is treated as a quasiexternal parameter since it is depicted as a simple uniform mass floating on the water surface. Its 
density and salinity are constant in both time and space, and the vertical temperature gradient within the ice is taken to be linear. Its thermal conductivity is determined only at the ice-water boundary, which is warmest and therefore limiting. An upper limit is applied to the calculated upward heat flux density through the ice so that at no time may the flux through the ice exceed that over open water; 3) mechanical lead closure is disallowed; 4) snow cover over the lead's surface is not modelled; 5) super-cooling of surface waters (Coachman 1966) is not portrayed; 6) as convection-induced mixing occurs instantaneously

TABLE 1. Profiles of primary environmental variables used.

\begin{tabular}{|c|c|c|c|c|c|c|}
\hline $\begin{array}{l}\text { Depth } \\
\text { (m.) }\end{array}$ & A & B & $\begin{array}{r}\text { Profile } \\
\mathrm{C}\end{array}$ & D & $\mathbf{E}$ & $\mathbf{F}$ \\
\hline \multicolumn{7}{|c|}{ Horizontal current magnitude, $u, \mathrm{~cm} . \mathrm{sec}^{-1}$} \\
\hline $\begin{array}{l}\text { Water } \\
0 \\
5 \\
10 \\
15 \\
20 \\
25 \\
30 \\
35 \\
40 \\
45 \\
50\end{array}$ & $\begin{array}{r}\text { ire, } T,{ }^{\circ} \mathrm{C} . \\
-1.50 \\
-1.40 \\
-1.30 \\
-1.20 \\
-1.10 \\
-1.00 \\
-0.90 \\
-0.80 \\
-0.70 \\
-0.60 \\
-0.50\end{array}$ & $\begin{array}{l}-1.50 \\
-1.49 \\
-1.48 \\
-1.47 \\
-1.46 \\
-1.45 \\
-1.44 \\
-1.43 \\
-1.42 \\
-1.41 \\
-1.40\end{array}$ & $\begin{array}{l}-1.68 \\
-1.68 \\
-1.68 \\
-1.67 \\
-1.66 \\
-1.65 \\
-1.64 \\
-1.63 \\
-1.62 \\
-1.61 \\
-1.60\end{array}$ & $\begin{array}{l}-1.82 \\
-1.82 \\
-1.82 \\
-1.82 \\
-1.81 \\
-1.80 \\
-1.79 \\
-1.78 \\
-1.77 \\
-1.76 \\
-1.75\end{array}$ & & \\
\hline $\begin{array}{l}\text { Water } \\
0 \\
5 \\
10 \\
15 \\
20 \\
25 \\
30 \\
35 \\
40 \\
45 \\
50\end{array}$ & $\begin{array}{r}\% \% 0 . \\
28.00 \\
28.50 \\
29.00 \\
29.50 \\
30.00 \\
30.50 \\
31.00 \\
31.50 \\
32.00 \\
32.50 \\
33.00\end{array}$ & $\begin{array}{l}28.00 \\
28.01 \\
28.02 \\
28.03 \\
28.04 \\
28.05 \\
28.06 \\
28.07 \\
28.08 \\
28.09 \\
28.10\end{array}$ & $\begin{array}{l}31.00 \\
31.01 \\
31.02 \\
31.06 \\
31.15 \\
31.25 \\
31.35 \\
31.45 \\
31.55 \\
31.65 \\
31.75\end{array}$ & $\begin{array}{l}33.51 \\
33.52 \\
33.53 \\
33.55 \\
33.57 \\
33.60 \\
33.63 \\
33.66 \\
33.69 \\
33.72 \\
33.75\end{array}$ & & \\
\hline
\end{tabular}

TABLE 2. Schedule of runs conducted with the model.

\begin{tabular}{|c|c|c|c|}
\hline $\begin{array}{l}\text { Run } \\
\text { number }\end{array}$ & & $\underset{\mathbf{T}}{\text { ble profile }} \mathbf{S}$ & $\begin{array}{c}\text { Period of integration } \\
\text { (days) }\end{array}$ \\
\hline $\begin{array}{r}1 \\
2 \\
3 \\
4 \\
5 \\
6 \\
7 \\
8 \\
9 \\
10 \\
11 \\
12 \\
13 \\
14\end{array}$ & $\begin{array}{l}\text { A } \\
\text { A } \\
\text { A } \\
\text { A } \\
\text { B } \\
\text { B } \\
\text { B } \\
\text { B } \\
\text { C } \\
\text { D } \\
\text { E } \\
\mathbf{E} \\
\mathbf{E} \\
\text { F }\end{array}$ & $\begin{array}{ll}\mathbf{A} & \mathbf{A} \\
\mathbf{A} & \mathbf{B} \\
\mathbf{B} & \mathbf{A} \\
\mathbf{B} & \mathbf{B} \\
\mathbf{A} & \mathbf{A} \\
\mathbf{A} & \mathbf{B} \\
\mathbf{B} & \mathbf{A} \\
\mathbf{B} & \mathbf{B} \\
\mathbf{A} & \mathbf{B} \\
\mathbf{A} & \mathbf{B} \\
\mathbf{C} & \mathbf{C} \\
\mathbf{D} & \mathbf{D} \\
\mathbf{D} & \mathbf{D} \\
\mathbf{A} & \mathbf{B}\end{array}$ & $\begin{array}{r}2 \\
2 \\
2 \\
2 \\
2 \\
2 \\
2 \\
2 \\
2 \\
2 \\
2 \\
2 \\
30 \\
2\end{array}$ \\
\hline
\end{tabular}


in the model, so also does surface ice melting whenever heat is brought to the surface by convection. This results in a major artificiality in that, although heat and salt are conserved in the water-ice model, heat brought to the surface at a point under the ice cover immediately melts ice at that point until no further surface heat is available for melting. Therefore, under this 'instantaneous point convection/point melting' limitation it is not possible for surface heat to be advected downstream under an ice cover to promote downstream melting. Only in cases where no ice is present to be melted may this heat be advected downstream.

\section{RESULTS}

Some results of integrating the model using the combinations of environmental variables summarized in Tables 1 and 2 are presented in graphic and tabular form. Primary output variables treated are: maximum ice thicknesses occurring in the lead for each run versus time over a 2 day period (Fig. 2); ice thicknesses occurring at each surface grid point for each run after 2 days of freezing versus distance downstream of the lead's source boundary (Fig. 3); cumulative surface heat loss densities occurring at each surface grid point for each run after 2 days of freezing versus distance downstream of the lead's source boundary (Fig. 4); maximum ice thicknesses and mean surface heat loss densities occurring in the lead for run 13, plotted versus time over a 30-day period (Fig. 5); and mean surface heat loss densities and maximum depths of penetration of convective overturn after 2 days of freezing (Table 3). Due to the numerical nature of the model, maximum depths of convective overturn should be treated as boundary depths (resolution limited by vertical grid spacing) rather than as precise depths as would be indicated by continuous schemes.

TABLE 3. A. 48-hour mean-surface heat loss densities (x $10^{2}$ cal.-cm. $\left.^{-2}\right)$; B. Maximum depth of convective overturn (m.).

\begin{tabular}{ccr}
\hline $\begin{array}{c}\text { Run } \\
\text { number }\end{array}$ & A. & B. \\
\hline 1 & 14.9 & 5 \\
2 & 17.0 & 10 \\
3 & 13.7 & 5 \\
4 & 14.9 & 10 \\
5 & 14.9 & 5 \\
6 & 23.2 & 20 \\
7 & 13.7 & 5 \\
8 & 14.5 & 20 \\
11 & 13.8 & 15 \\
12 & 14.2 & 15 \\
\hline
\end{tabular}

\section{DISCUSSION}

Through the time-dependent temperature-salinity-density fields generated in the lead model, an insight was afforded into the process of lead reclosure, as well as the hydrodynamic validity of the model under certain conditions. 

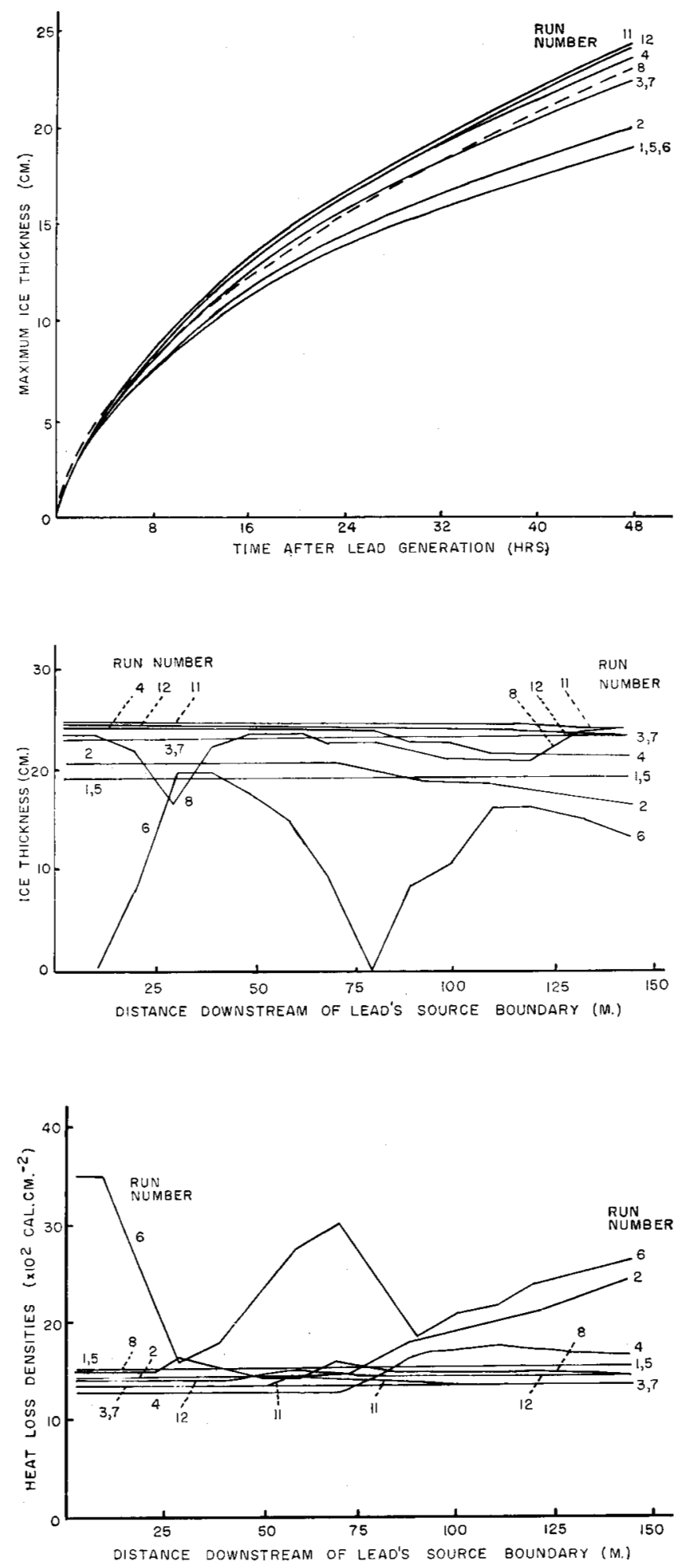

FIG. 2. Maximum ice thicknesses occurring in the lead vs. time, runs $1-8,11,12$.

FIG. 3. Ice thicknesses at each surface grid point vs. distance downstream of the lead's source boundary, runs 1-8, $11,12$.

FIG. 4. Cumulative surface heat loss densities occurring at each surface grid point vs. distance downstream of the lead's source boundary, runs 1-8, 11, 12 . 
Water column stability. Most pronounced was the very strong role played by the near-surface vertical salinity gradient in maintaining water column stability. A strong halocline near the surface tended to insulate deeper waters in the lead from the thermodynamic activity occurring at the surface and tended to result in more rapid ice formation. Surface waters whose densities had been increased by salt rejected by newly forming ice were not able to mix vertically until density instabilities occurred in the surface region, thus inducing convective overturn. Since the presence of a strong surface halocline would require higher surface salinity accumulations and hence permit more ice formation and associated salt rejection before this surface layer would become unstable, a strong halocline would be expected to inhibit convective overturn, both in frequency of occurrence and depth of penetration in the lead. Added to this insulating effect is the fact that, as surface salinities increase, surface freezing temperatures correspondingly decrease so that freezing rates are proportionately lowered. The role played by the vertical temperature gradient in lead thermodynamics was strongly dependent upon the halocline, since density changes in sea water at temperatures near the freezing point are almost totally a function of salinity changes. However, in situations wherein weak vertical salinity gradients (poor insulation) and strong vertical temperature gradients coexisted, convective overturn resulted in relatively large quantities of heat being transported to the surface. Freezing and associated salt rejection were thus inhibited and surface melting was induced. The effect of horizontal current magnitudes on lead stability appeared, as in the case of the thermocline, to be secondary to the effect of the halocline. Strong currents will advect surface salt accumulations out of the lead relatively quickly, and will in general allow less time for lead thermodynamics to affect a given parcel of water. Thus, the current also acts as an insulating agent.

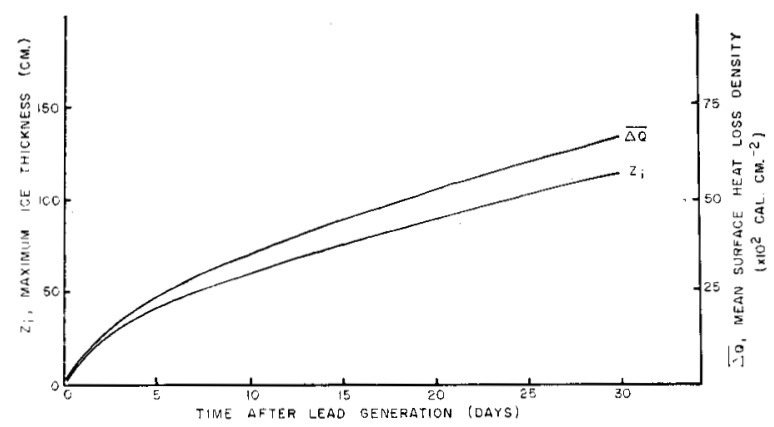

FIG. 5. Maximum ice thicknesses and mean-surface heat loss densities occurring in the lead vs. time, run 13.

Ice growth rates. When examining the maximum ice thicknesses occurring anywhere on the lead's surface as a function of time, in all cases high ice growth rates were associated with weak vertical temperature gradients and vice versa. Furthermore, current strength was relatively unimportant in changing growth rates when either strong haloclines were present, or when weak thermoclines coexisted with weak haloclines. The effect of the thermocline appears then to dominate in determining surface freezing rates, with the current and the halocline acting as insulating agents. 
Ice thickness profiles. Ice thickness profiles across the lead varied considerably with different variable combinations. Uniform or nearly uniform ice thickness profiles were in all cases associated with strong haloclines. Variations occurred where weak haloclines existed, growing larger where weak haloclines and strong thermoclines occurred together. The greatest surface irregularity, both by amplitude and spatial frequency of variation, was found where weak currents, weak haloclines, and strong thermoclines were present. These irregularities are discussed further under model hydro-thermodynamic validity. The halocline was the dominant variable in determining uniformity of ice thickness across the lead through the insulation it afforded the surface from heat at depth in the lead. When convective overturn occurred as a result of increases in surface salinity, surface freezing rates were altered at the point of convective overturn and produced surface irregularities. Since rejected salt is continuously advected downstream during the freezing process, there will exist horizontal salinity gradients which, when exceeding a given downstream stability limit, will induce convective overturn and surface melting at that point. Downstream of that point then, surface waters are diluted due to that melting, thus experiencing increased freezing rates since their freezing point has effectively been raised. The near-surface thermocline appeared to affect surface ice uniformity through determining the amount of heat transported to the surface during convective overturn, and thus the amount of melting and dilution occurring. Strong thermoclines resulted in greater nonuniformity. Finally, current strength appeared to act analogously to the halocline as an insulating agent, though less effectively. By flushing surface salt accumulations out of the lead more rapidly, a strong current appears to inhibit convective overturn and hence variations in ice uniformity.

Surface heat loss. Surface heat loss densities varied across the lead's surface in response to ice thickness profiles. Uniformity of surface heat loss density was directly related to the uniformity of the ice profile, whereas relative magnitudes of heat loss density were inversely related to relative ice thicknesses.

Model hydro-thermodynamic validity. The extreme case of lead instability and surface non-uniformity requires special comment. A high mean surface heat loss density characterized this case, which was expected as a result of its highly nonuniform ice profile. However, the lack of evidence of these highly non-uniform ice covers occurring in nature in the absence of mechanical deformation forces prompted further analysis by means of runs 9,10 and 14 (not illustrated). The primary cause of this aggravated non-uniformity appeared to be due to the instantaneous nature of the convection artifice acting in conjunction with the instantaneous point melting/point freezing artifice. Where a weak current, weak halocline and strong thermocline are present, these two artifices would tend to produce large, spatially-periodic variations in ice thickness. Beginning with the furthest upstream occurrence of convection in the lead owing to surface salinity reaching a certain critical value, the convection artifice instantaneously brings heat to the surface which in turn instantaneously melts ice at that same point. Downstream of this, ice formation is accelerated owing to dilution of surface waters, and the downstream salinity gradient begins to increase again to a critical value. Thus these two artifices appear to combine to produce a 'leap frog' effect 
of alternately-spaced melting and accelerated ice formation, with the horizontal current and vertical temperature and salinity gradients acting as scaling factors.

Results of run 14 proved to be of particular interest through the insight afforded into the hydro-thermodynamics of the lead model. Since no current was present, there was no horizontal coupling between model grid points. As a result, although freezing progressed uniformly over the lead surface, strong differential horizontal density gradients developed along the 'source' boundary as cooling progressed. Of prime interest however was the graphic illustration of the role played by the current as a convective overturn scaling factor. With zero current, a strong temperature gradient and a weak salinity gradient, freezing-induced convective overturn penetrated to a depth of $35 \mathrm{~m}$. roughly 18 hours after lead generation. Without the flushing action of a horizontal current or the insulating effect of a strong halocline, the effects of surface thermodynamics were felt much deeper in the lead. It appears probable then, that in cases where weak currents and weak haloclines coexist in open leads (marginal vertical stability), surface freezing and the resulting convection will induce substantial vertical and horizontal gradients in both temperature and salinity. This represents a very effective and perhaps significant mechanism of coupling the ice and deeper water across the mixed layer. A more detailed model would be required adequately to study the implications of this process.

\section{CONCLUSIONS}

The near-surface halocline appears to exert the dominant force in maintaining vertical density stability in the lead, closely followed by the effect of the horizontal current. Both the halocline and the horizontal current act so as to insulate the deeper waters of the lead from surface thermodynamics, the former through directly providing a strong density gradient and therefore a highly stable stratification less easily penetrated by convection, the latter through flushing surface salt accumulations out of the lead and thus limiting surface density increases. In this manner, the halocline and the horizontal current appear to act as scaling factors for convection in the lead, affecting temporal and spatial frequency of convection as well as its depth of penetration.

The near-surface thermocline appears to be the dominant variable influencing the rate of ice formation. The strength of the thermocline is a measure of the amount of heat at depth available to be transported to the ice-water boundary by eddy diffusion, convection and advection. Higher freezing rates were associated with weak thermoclines.

Mean surface heat loss densities were in general high in cases where strong thermoclines existed with well-developed convection, although the instantaneous point convection/point melting artifices tended to overly emphasize heat losses through producing non-uniform ice covers. This conclusion could prove to be of significance to critical examinations of the heat budget over large areas of the Arctic in which significant variations in current fields and near-surface stratification might reasonably be expected. From these results it appears that purely oceanographic factors impose secondary but perhaps significant constraints on 
the rate of refreezing, the degree of development of oceanic convection, and surface heat losses in the Arctic. This would suggest, for example, that the heat flux per lead would be different in the region of the transpolar drift than in the vicinity of the Beaufort Gyre.

Representative freezing rates, ice thickness profiles, and surface heat loss densities found in integrating the model using real case variables agreed well with values in the literature. The effect of downstream salt accumulation was noticed in slightly decreasing downstream ice thicknesses. This downstream melting of thicker ice due to surface salt accumulations during upstream ice formation acts in an opposite sense to the accretion due to super-cooling that seems to occur in the summer (Coachman 1966).

Although the surface boundary of the model could be considerably more sophisticated in its treatment of energy fluxes and transport processes, models already exist which have this sophistication, notably that of Maykut and Untersteiner $(1969,1971)$. Coupling the model at hand to their model would therefore seem a more reasonable approach to refinement at the surface boundary in order to model air-ice-sea interactions and mass-energy balances. The hydrodynamics occurring in a refreezing lead, however, are not yet accurately modelled, nor are they fully understood despite the results of the research. Extension of this work would develop a further understanding of these processes as well as a more accurate model. Incorporation of accelerations resulting from thermodynamicallygenerated horizontal pressure gradients and more precisely defining the surface heat budget (including sub-surface radiational heating and internal calculation of all open-water surface heat fluxes) would considerably refine the model. Perhaps the most significant refinement would be the removal of the instantaneous point melting limitation, thus permitting downstream advection of warmer-thanfreezing-point waters under an ice cover and thus allowing a more general application of the model.

\section{ACKNOWLEDGEMENTS}

We are sincerely grateful to the United States Navy for providing the facilities for conducting this research.

\section{REFERENCES}

Badgley, F. 1. 1961. Heat balance at the surface of the Arctic Ocean. Proceedings of the Western Snow Conference, Spokane, pp. 101-04.

1966. Heat budget at the surface of the Arctic Ocean. Proceedings of the Symposium on the Arctic Heat Budget and Atmospheric Circulation. Santa Monica: The Rand Corporation Report RM-5233-NSF, pp. 267-77.

BILELLo, M. 1961. Formation, growth and decay of sea ice in the Canadian Arctic Archipelago. Arctic, 14: 3-24.

CoAchman, L. K. 1966. Production of supercooled water during sea ice formation. Proceedings of the Symposium on the Arctic Heat Budget and Atmospheric Circulation. Santa Monica: The Rand Corporation Report RM-5233-NSF, pp. 497-529.

COACHMAN, L, K. and C. A. BARNES. 1961. The contribution of Bering Sea water to the Arctic Ocean. Arctic, 14: 147-61. 
15: $251-77$.

1962. Surface water in the Eurasian Basin of the Arctic Ocean. Arctic,

DORONIN, Y. P. 1966. Characteristics of the heat exchange. Proceedings of the Symposium on the Arctic Heat Budget and Atmospheric Circulation. Santa Monica: The Rand Corporation Report RM-5233-NSF, pp. 247-66.

FLETCHER, J. o. 1966. The arctic heat budget and atmospheric circulation. Proceedings of the Symposium on the Arctic Heat Budget and Atmospheric Circulation. Santa Monica: The Rand Corporation Report RM-5233-NSF, pp. 23-43.

FOSTER, T. D. 1968. Haline convection induced by the freezing of sea water. Journal of Geophysical Research, 73: 1933-38.

1969. Experiments on haline convection induced by the freezing of sea water. Journal of Geophysical Research, 74: 6967-74.

LAKE, R. A. and E. L. LEWIS. 1970. Salt rejection by sea ice during growth. Journal of Geophysical Research, 75: 583-97.

LEWIS, E. L. and E. R. WALKER. 1970. The water structure under a growing sea ice sheet. Journal of Geophysical Research, 75: 6836-45.

MAYKUT, G. A. and N. UNTERSTEINER. 1969. Numerical prediction of the thermodynamic response of arctic sea ice to environmental changes. Santa Monica: The Rand Corporation Report RM-6093-PR, 173 pp.

1971. Some results from a time-dependent thermodynamic model of sea ice. Journal of Geophysical Research, 76: 1550-75.

METTLER, A. J. and N. S. STEHLE. 1966. Ice engineering - analysis of the growth of sea ice. Port Hueneme: U.S. Naval Civil Engineering Laboratory Technical Report R-497, $46 \mathrm{pp}$.

MUENCH, R. D. 1971. The physical oceanography of the northern Baffin Bay region. The Arctic Institute of North America, Baffin Bay-North Water Project, Scientific Report No. $1,150 \mathrm{pp}$.

SCHAUS, R. H. 1971. A thermodynamic model of a central arctic open lead. Master's Thesis, Naval Postgraduate School, Monterey, 86 pp.

STERN, M. E. and J. S. TURNER. 1969. Salt fingers and convecting layers. Deep Sea Research, 16: $497-511$.

vowINCKEL, E. 1964. Heat flux through the polar ocean ice. McGill University, Department of Meteorology, Arctic Meteorology Research Group, Publication in Meteorology No. 70, Scientific Report No. 12, 15 pp. 